\title{
Results of Prevention of REStenosis with Tranilast and its Outcomes (PRESTO) Trial
}

David R. Holmes, Jr, Michael Savage, J.-M. LaBlanche, Lars Grip, P.W. Serruys, Peter Fitzgerald, David Fischman, Sheldon Goldberg, Jeffrey A. Brinker, A.M. Zeiher, Leonard M. Shapiro, James Willerson, Barry R. Davis, James J. Ferguson, Jeffrey Popma, Spencer B. King, III, A. Michael Lincoff, James E. Tcheng, Robert Chan, Jeffrey R. Granett and Marcia Poland

Circulation 2002;106;1243-1250; originally published online Aug 19, 2002;

DOI: 10.1161/01.CIR.0000028335.31300.DA

Circulation is published by the American Heart Association. 7272 Greenville Avenue, Dallas, TX 72514

Copyright @ 2002 American Heart Association. All rights reserved. Print ISSN: 0009-7322. Online ISSN: $1524-4539$

The online version of this article, along with updated information and services, is located on the World Wide Web at:

http://circ.ahajournals.org/cgi/content/full/106/10/1243

Subscriptions: Information about subscribing to Circulation is online at http://circ.ahajournals.org/subsriptions/

Permissions: Permissions \& Rights Desk, Lippincott Williams \& Wilkins, 351 West Camden Street, Baltimore, MD 21202-2436. Phone 410-5280-4050. Fax: 410-528-8550. Email:

journalpermissions@1ww.com

Reprints: Information about reprints can be found online at http://www.lww.com/static/html/reprints.html 


\title{
Results of Prevention of REStenosis with Tranilast and its Outcomes (PRESTO) Trial
}

\author{
David R. Holmes, Jr, MD; Michael Savage, MD; J.-M. LaBlanche, MD; Lars Grip, MD; \\ P.W. Serruys, MD, PhD; Peter Fitzgerald, MD; David Fischman, MD; Sheldon Goldberg, MD; \\ Jeffrey A. Brinker, MD; A.M. Zeiher, PhD; Leonard M. Shapiro, MD; James Willerson, MD; \\ Barry R. Davis, MD, PhD; James J. Ferguson, MD; Jeffrey Popma, MD; Spencer B. King III, MD; \\ A. Michael Lincoff, MD; James E. Tcheng, MD; Robert Chan, MD; \\ Jeffrey R. Granett, MD; Marcia Poland, MA
}

Background-Restenosis after percutaneous coronary intervention (PCI) is a major problem affecting $15 \%$ to $30 \%$ of patients after stent placement. No oral agent has shown a beneficial effect on restenosis or on associated major adverse cardiovascular events. In limited trials, the oral agent tranilast has been shown to decrease the frequency of angiographic restenosis after PCI.

Methods and Results - In this double-blind, randomized, placebo-controlled trial of tranilast (300 and $450 \mathrm{mg}$ BID for 1 or 3 months), 11484 patients were enrolled. Enrollment and drug were initiated within 4 hours after successful PCI of at least 1 vessel. The primary end point was the first occurrence of death, myocardial infarction, or ischemia-driven target vessel revascularization within 9 months and was $15.8 \%$ in the placebo group and $15.5 \%$ to $16.1 \%$ in the tranilast groups ( $P=0.77$ to 0.81$)$. Myocardial infarction was the only component of major adverse cardiovascular events to show some evidence of a reduction with tranilast ( $450 \mathrm{mg}$ BID for 3 months): $1.1 \%$ versus $1.8 \%$ with placebo ( $P=0.061$ for intent-to-treat population). The primary reason for not completing treatment was $\geq 1$ hepatic laboratory test abnormality ( $11.4 \%$ versus $0.2 \%$ with placebo, $P<0.01)$. In the angiographic substudy composed of 2018 patients, minimal lumen diameter (MLD) was measured by quantitative coronary angiography. At follow-up, MLD was $1.76 \pm 0.77 \mathrm{~mm}$ in the placebo group, which was not different from MLD in the tranilast groups (1.72 to $1.78 \pm 0.76$ to $80 \mathrm{~mm}, P=0.49$ to 0.89 ). In a subset of these patients $(\mathrm{n}=1107)$, intravascular ultrasound was performed at follow-up. Plaque volume was not different between the placebo and tranilast groups (39.3 versus 37.5 to $46.1 \mathrm{~mm}^{3}$, respectively; $P=0.16$ to 0.72 ).

Conclusions-Tranilast does not improve the quantitative measures of restenosis (angiographic and intravascular ultrasound) or its clinical sequelae. (Circulation. 2002;106:1243-1250.)

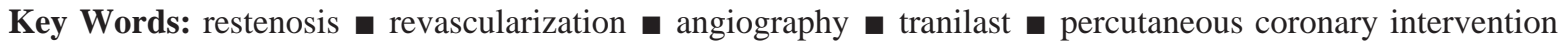

$\mathrm{P}$ revention of restenosis after percutaneous coronary intervention (PCI) remains a challenge despite stent deployment. ${ }^{1-4}$ Although the frequency of restenosis has decreased to $15 \%$ to $30 \%$ with the widespread use of stent implantation, this still represents a large population of patients, many of whom will require a further revascularization procedure for restenosis. Systemic pharmacological approaches, in general, have been unsuccessful. Therefore, the results of 2 small placebo-controlled angiographic trials showing a statistically and clinically significant reduction in angiographic restenosis with tranilast 5 ,6 were seen as an opportunity to definitively assess this agent for the prevention of restenosis.

Tranilast inhibits the release or production of chemical mediators and cytokines by inflammatory cells and macrophages and interferes with the proliferation and migration of vascular medial smooth muscle cells induced by platelet-

Received March 25, 2002; revision received June 10, 2002; accepted June 18, 2002.

From the Mayo Clinic (D.R.H.), Rochester, Minn; Jefferson University Hospital (M.S.), Philadelphia, Pa; Hospital Cardiologique (J.-M.L.), Lille, France; Gothenburg University (L.G.), Gothenburg, Sweden; Heartcentre (P.W.S.), Rotterdam, the Netherlands; Stanford University (P.F.), Stanford, Calif; Jefferson University Angiography Core Lab (D.F.), Philadelphia, Pa; Cooper Hospital University Medical Center (S.G.), Camden, NJ; Johns Hopkins University Hospital (J.A.B.), Baltimore, Md; Johann-Wolfgang-Goethe Universitaet (A.M.Z.), Hesse, Germany; Papworth Hospital (L.M.S.), Cambridge, UK; University of Texas Medical School (J.W.), Texas Heart Institute (J.W., J.J.F.), and University of Texas School of Public Heath (B.R.D.), Houston, Tex; Brigham and Women's Hospital (J.P.), Boston, Mass; Emory University Hospital (S.B.K.), Atlanta, Ga; Cleveland Clinic Foundation (A.M.L.), Cleveland, Ohio; Duke University (J.E.T.), Durham, NC; and GlaxoSmithKline (R.C., J.R.G., M.P.), Collegeville, Pa.

Dr Davis served as consultant to and/or received honoraria from Abbott Laboratories, Forest Labs, Merck, Pfizer, Pharmacia, and GlaxoSmithKline. Guest editor for this article was David P. Faxon, MD, The University of Chicago, Chicago, Ill.

The Appendix is available in the online-only Data Supplement at http://www.circulationaha.org.

Reprint requests to David R. Holmes, Jr, MD, Division of Cardiovascular Diseases and Internal Medicine, Mayo Clinic, 200 First St SW, Rochester, MN 55905.

(C) 2002 American Heart Association, Inc. 
TABLE 1. Patient Characteristics

\begin{tabular}{|c|c|c|c|c|c|}
\hline \multirow[b]{2}{*}{$\begin{array}{l}\text { Treatment Status and Patient } \\
\text { Characteristics }\end{array}$} & \multirow[b]{2}{*}{$\begin{array}{c}\text { Placebo } \\
(n=2298)\end{array}$} & \multicolumn{2}{|c|}{ Tranilast BID for $1 \mathrm{mo}$} & \multicolumn{2}{|c|}{ Tranilast BID for $3 \mathrm{mo}$} \\
\hline & & $\begin{array}{c}300 \mathrm{mg} \\
(\mathrm{n}=2306)\end{array}$ & $\begin{array}{c}450 \mathrm{mg} \\
(\mathrm{n}=2280)\end{array}$ & $\begin{array}{c}300 \mathrm{mg} \\
(\mathrm{n}=2300)\end{array}$ & $\begin{array}{c}450 \mathrm{mg} \\
(\mathrm{n}=2300)\end{array}$ \\
\hline US/rest of world, \% & $43.8 / 56.2$ & $43.8 / 56.2$ & $43.9 / 56.1$ & $43.8 / 56.2$ & $43.7 / 56.3$ \\
\hline Completed/withdrew treatment, \% & $85.3 / 14.7$ & $79.0 / 21.0$ & $75.6 / 24.4$ & $76.5 / 23.5$ & $68.9 / 31.1$ \\
\hline Males & $1777(77.3)$ & $1774(76.9)$ & $1771(77.7)$ & $1785(77.6)$ & $1786(77.7)$ \\
\hline Age, y & $60.2 \pm 10.5$ & $60.1 \pm 10.4$ & $60.3 \pm 10.4$ & $60.4 \pm 10.5$ & $60.2 \pm 10.3$ \\
\hline Diabetes & $553(24.1)$ & $523(22.7)$ & $533(23.4)$ & $546(23.7)$ & $529(23.0)$ \\
\hline Hypertension & $1429(62.2)$ & $1391(60.3)$ & $1350(59.2)$ & $1435(62.4)$ & $1408(61.2)$ \\
\hline Congestive heart failure & $144(6.3)$ & $145(6.3)$ & $142(6.2)$ & $124(5.4)$ & $141(6.1)$ \\
\hline Statin use & $1703(74.1)$ & $1702(73.8)$ & $1646(72.2)$ & $1680(73.0)$ & $1661(72.2)$ \\
\hline History of angioplasty & $705(30.7)$ & $704(30.5)$ & $716(31.4)$ & $738(32.1)$ & $694(30.2)$ \\
\hline History of $\mathrm{CABG}$ & $705(30.7)$ & $704(30.5)$ & $716(31.4)$ & $738(32.1)$ & $694(30.2)$ \\
\hline History of Ml & $890(38.7)$ & $904(39.2)$ & $873(38.3)$ & $911(39.6)$ & $875(38.0)$ \\
\hline Recent MI (index PCl reason) & $293(12.7)$ & $305(13.3)$ & $302(13.3)$ & $282(12.2)$ & $300(13.1)$ \\
\hline Unstable angina & $649(28.2)$ & $672(29.1)$ & $664(29.1)$ & $652(28.4)$ & $680(29.6)$ \\
\hline Multivessel disease & $406(17.7)$ & $402(17.4)$ & $394(17.3)$ & $431(18.7)$ & $416(18.1)$ \\
\hline Restenotic vessel & $349(15.2)$ & $385(16.7)$ & $355(15.6)$ & $372(16.2)$ & $362(15.7)$ \\
\hline In-stent restenosis & $266(11.6)$ & $306(13.3)$ & $285(12.5)$ & $304(13.2)$ & $286(12.4)$ \\
\hline No. target vessels & $1.2 \pm 0.4$ & $1.2 \pm 0.4$ & $1.2 \pm 0.4$ & $1.2 \pm 0.4$ & $1.2 \pm 0.4$ \\
\hline No. target lesions & $1.4 \pm 0.7$ & $1.4 \pm 0.7$ & $1.4 \pm 0.7$ & $1.4 \pm 0.7$ & $1.4 \pm 0.7$ \\
\hline \multicolumn{6}{|l|}{ Target vessel site* } \\
\hline Graft & $107(4.7)$ & $92(4.0)$ & $119(5.2)$ & $104(4.5)$ & $103(4.5)$ \\
\hline LAD & $902(39.3)$ & $900(39.0)$ & $863(37.9)$ & $892(38.8)$ & $932(40.5)$ \\
\hline Right coronary artery & 1069 (32.3) & $1124(33.8)$ & 1066 (32.6) & $1093(32.5)$ & $1094(32.4)$ \\
\hline Circumflex & $792(23.9)$ & 738 (22.2) & $772(23.6)$ & $806(24.0)$ & 747 (22.1) \\
\hline Left main & $29(0.9)$ & $20(0.6)$ & $20(0.6)$ & $19(0.6)$ & $30(0.9)$ \\
\hline Angioplasty with stent(s) & 1935 (84.2) & $1920(83.3)$ & 1917 (84.1) & $1921(83.5)$ & $1944(84.5)$ \\
\hline Lesion diameter $<2 \mathrm{~mm}$ & $548(99.5)$ & $536(98.4)$ & 527 (98.7) & 554 (99.3) & $550(98.6)$ \\
\hline \multicolumn{6}{|l|}{ Vessel length, mm } \\
\hline$>20$ & $48(8.7)$ & $62(11.4)$ & $50(9.4)$ & $60(10.8)$ & $73(13.1)$ \\
\hline $10-20$ & $279(50.6)$ & $274(50.3)$ & $266(49.8)$ & $277(49.6)$ & $262(47.0)$ \\
\hline Vessel stenosis, \% & $84.1 \pm 12.0$ & $84.4 \pm 12.0$ & $84.3 \pm 11.8$ & $84.0 \pm 12.4$ & $83.8 \pm 12.5$ \\
\hline \multicolumn{6}{|l|}{ Lesion morphology } \\
\hline Type A & 557 (17.3) & $529(16.3)$ & $522(16.4)$ & $557(17.0)$ & $515(15.8)$ \\
\hline Type B1 & $977(30.4)$ & 1054 (32.4) & 1014 (31.8) & 1014 (30.9) & $1011(30.9)$ \\
\hline Type B2 & 1194 (37.2) & $1206(37.1)$ & 1149 (36.0) & 1187 (36.2) & $1220(37.3)$ \\
\hline Type C & 477 (14.9) & 452 (13.9) & $496(15.6)$ & $513(15.7)$ & $514(15.7)$ \\
\hline Total occlusion & $202(6.3)$ & $232(7.1)$ & $211(6.6)$ & $222(6.8)$ & $233(7.1)$ \\
\hline GPIIb/Illa agents & 855 (37.2) & $831(36.0)$ & $827(36.3)$ & $830(36.1)$ & $850(37.0)$ \\
\hline Thienopyridines & $2061(90)$ & 2056 (89) & $2053(90)$ & 2052 (89) & $2069(90)$ \\
\hline
\end{tabular}

derived growth factor and transforming growth factor- $\beta_{1}{ }^{7}$ The anti-inflammatory effects of tranilast have been demonstrated by the inhibition of prostaglandin $E_{2}$, thromboxane $B_{2}$, transforming growth factor- $\beta_{1}$, and interleukin- 8 in in vitro models and by attenuation of the proinflammatory activity of human monocytes. ${ }^{7}$ In addition, in various animal models, tranilast has been shown to reduce neointimal and adventitial thickening after vascular wall injury. ${ }^{8,9}$

In 2 angiographic trials, tranilast $(600 \mathrm{mg}$ a day for 3 months) decreased the proportion of nonstented patients with restenosis assessed by quantitative coronary angiography. Restenosis occurred in $60 \%$ of the patients treated with 
TABLE 2. Results of Primary Composite End Point of MACE

\begin{tabular}{|c|c|c|c|c|c|}
\hline \multirow[b]{2}{*}{$\begin{array}{l}\text { Primary Efficacy } \\
\text { End Point }\end{array}$} & \multirow[b]{2}{*}{$\begin{array}{l}\text { Placebo } \\
(n=2298)\end{array}$} & \multicolumn{2}{|c|}{ Tranilast BID for $1 \mathrm{mo}$} & \multicolumn{2}{|c|}{ Tranilast BID for $3 \mathrm{mo}$} \\
\hline & & $\begin{array}{c}300 \mathrm{mg} \\
(\mathrm{n}=2306)\end{array}$ & $\begin{array}{c}450 \mathrm{mg} \\
(\mathrm{n}=2280)\end{array}$ & $\begin{array}{c}300 \mathrm{mg} \\
(\mathrm{n}=2300)\end{array}$ & $\begin{array}{c}450 \mathrm{mg} \\
(\mathrm{n}=2300)\end{array}$ \\
\hline At least 1 MACE, ${ }^{*} n(\%)$ & $358(15.7)$ & $352(15.4)$ & $351(15.5)$ & $363(16.0)$ & $364(16.0)$ \\
\hline Hazard ratio $(95 \% \mathrm{Cl})$ & & $0.98(0.85-1.14)$ & $0.98(0.84-1.13)$ & $1.02(0.88-1.18)$ & $1.02(0.88-1.18)$ \\
\hline$P$ vs placebot & & 0.81 & 0.77 & 0.81 & 0.77 \\
\hline
\end{tabular}

*Risks are Kaplan-Meier product-limit estimates.

†Derived from log-rank test.

placebo compared with $17 \%$ of the patients treated with tranilast in one of the trials $(P<0.001)^{5}$ and in $47 \%$ of the patients treated with placebo compared with $23 \%$ of the patients treated with tranilast in the other trial $(P<0.001) .{ }^{6}$ In a concurrent controlled study, patients who were stented were compared with those who were treated with both tranilast and stent ${ }^{10}$; there was a reduction in angiographic restenosis from $45 \%$ to $26 \%(P<0.05)$.

These trials, although provocative, were limited in scope and not adequately powered to document statistical differences in clinical outcomes. Accordingly, the Prevention of Restenosis With Tranilast and Its Outcomes (PRESTO) trial was designed to evaluate the effects of tranilast on major adverse cardiovascular events (MACEs) as well as quantitative angiographic and intravascular ultrasound (IVUS) end points.

\section{Methods}

\section{Study Design}

The PRESTO trial has been previously described and was a double-blind, placebo-controlled, parallel group study of patients after PCI. ${ }^{11}$ Successful PCI was defined as at least 1 vessel stenosis improved to $<50 \%$ residual stenosis without the occurrence of MACE before the first dose of study medication. The type of intervention performed was at investigator discretion, with the exclusion of experimental procedures, which included intracoronary radiation at the time of the trial. The protocol and informed consent were approved by a human research or ethics committee at each institution and the medical products agencies of the country when required. Patients were randomized to receive 1 of 5 treatments: placebo or tranilast at 300 or $450 \mathrm{mg}$ BID for 1 or 3 months. An angiographic substudy (2000 participants) was also prespecified; in this substudy, consecutive patients enrolled at selected sites were required to undergo follow-up angiography at 9 months (or sooner if clinically warranted). Some of these sites also obtained follow-up intravascular ultrasound (IVUS) evaluations (for 1000 patients). When the enrollment in the substudies was complete, these sites then enrolled the patients into the general protocol. A battery of laboratory tests was performed weekly for 4 weeks and then every other week for 2 months. All blood samples were analyzed by central laboratories that used the same methodology. Sites were instructed to use the term "hepatic function abnormal" when the result of at least 1 hepatic laboratory test was $>3$ times the upper limit of normal (ULN) and either alkaline phosphatase or total bilirubin reached ULN. Increases in transaminase levels and hyperbilirubinemia were defined as being 3 times ULN, and indirect bilirubin was defined as twice ULN. Abnormal creatinine was defined as an increase of $\geq 50 \%$ to a level of at least $1.2 \mathrm{mg} / \mathrm{dL}$ or a serum creatinine level of $>2 \mathrm{mg} / \mathrm{dL}$ on 2 consecutive occasions. Anemia was defined as a hemoglobin of $<10 \mathrm{~g} / \mathrm{dL}$ or a decrease from baseline of $\geq 2 \mathrm{~g} / \mathrm{dL}$.

The primary efficacy end point was the first occurrence of MACE within 9 months. Secondary end points were the components of MACE: all-cause mortality, myocardial infarction (MI), and ische- mia-driven target vessel revascularization. To avoid the criticism of angiographic restenosis being ascribed to this end point, the investigators had to identify and document signs of ischemia before a repeat angiogram. MI was defined as having at least 2 of the following: (1) characteristic ischemic pain lasting $\geq 20$ minutes, (2) creatine kinase $>3$ times ULN and creatine kinase-MB $>2$ times ULN, or (3) development of a new $>40-\mathrm{ms}$ Q waves in at least 2 adjacent ECG leads or new dominant $\mathrm{R}$ waves in $\mathrm{V}_{1}$. Ischemiadriven revascularization was defined as intervention for chest pain or a positive test for ischemia (exercise stress test, stress echocardiogram, 24-hour Holter monitor, resting ECG evidence of ST-segment depression or elevation in $>1$ lead, or radionuclide study showing a reversible defect). An independent clinical event committee confirmed any MACE. ${ }^{11}$ Other major secondary variables of interest included minimal lumen diameter (MLD) by quantitative coronary angiography and plaque volume by IVUS. As previously described, ${ }^{11}$ the angiograms and IVUS films were read by 2 laboratories each. Both angiography laboratories used the Cardiovascular Measurement System (Medis Medical Imaging Systems) for quantitative measurements. Restenosis was defined as $\geq 50 \%$ stenosis in a treated segment at follow-up. To compare the restenosis rates for tranilast with those previously reported by Tamai and colleagues,, 5 restenosis was also analyzed as $\geq 50 \%$ loss of acute gain.

\section{Power Calculations and Statistical Analysis}

An expected incidence of $18 \%$ in the primary MACE end point based on prior published trials, including the results of the Evaluation of Platelet IIB/IIIA Inhibitor for STENTing (EPISTENT) trial, ${ }^{12}$ was used for calculations of sample size. The overall type I error was selected so that the statistical evidence of efficacy would be equivalent to that provided by 2 positive trials at a level of significance of 0.05 and also to control for multiple group comparisons. Randomizing 2300 patients to each group provided $90 \%$ power to detect a reduction from $18 \%$ to $12.6 \%$ (30\% relative reduction) among any or all tranilast groups by using 2-sided log-rank tests with an overall $\alpha$ value of 0.00125 . $^{13,14}$

An intent-to-treat population was analyzed for the primary analysis, which was defined as all randomized patients who received at least 1 dose of study medication. The frequency of the first occurrence of MACE was analyzed by using a modified Bonferroni procedure. ${ }^{15}$ Significance levels for pairwise comparisons with placebo were derived from log-rank tests, stratifying for center. Cox proportional hazards models were used to calculate hazard ratios (tranilast/placebo) with associated 95\% CIs. In the model, the independent variables were center and treatment. Kaplan-Meier curves were calculated for MACE as well.

In the angiographic substudy, the minimum clinically relevant treatment difference was assumed to be $0.2 \mathrm{~mm}$ ( \pm SD of $0.7 \mathrm{~mm}$ ) between treatment groups at follow-up. ${ }^{4}$ Therefore, 400 patients per arm were required to detect this reduction with $93 \%$ power at an $\alpha$ value of 0.05 . To ensure that 2000 patients had follow-up angiograms, the protocol required that 2666 patients be enrolled in this substudy. Dichotomous restenosis rates were also analyzed.

In the IVUS substudy, the minimum treatment difference considered clinically relevant was assumed to be a $20 \%$ difference between treatment groups at follow-up. Based on a normal distribution curve in $\approx 100$ patients at the Stanford Core Laboratory, the mean plaque 


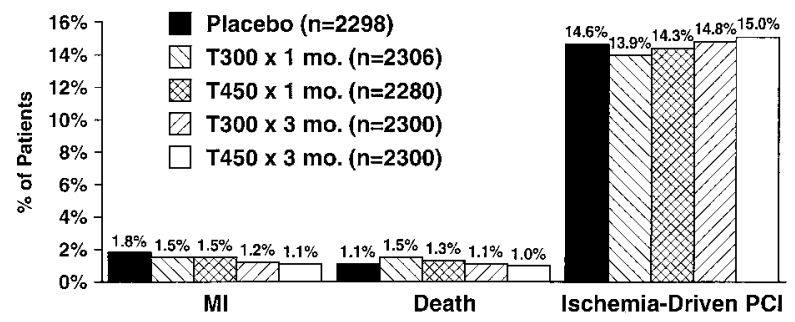

KEY: T300 $1 \mathrm{mo} .=$ tranilast, $300 \mathrm{mg}$ bid for one month; $\mathrm{T} 450 \times 1 \mathrm{mo} .=$ tranilast, $450 \mathrm{mg}$ bid for one month; $\mathrm{T} 300 \times 3 \mathrm{mo}$. = tranilast, $300 \mathrm{mg}$ bid for three months and T450 × 3 mo. = tranilast, $450 \mathrm{mg}$ bid for three months.

Note: \% of patients is higher than first occurrence of MACE because all events of the components of MACE are counted.

Figure 1. Percentage of patients with each component of MACE.

volume was expected to be $41.91 \mathrm{~mm}^{3}$ ( \pm SD of $17.67 \mathrm{~mm}^{3}$ ). With this assumption, 140 stented patients per group were required to detect a $20 \%$ reduction with $80 \%$ power at an $\alpha$ value of 0.05 .

\section{Results}

\section{Patient Characteristics}

Four hundred thirty-two centers (224 in the United States, 166 in Western Europe, 27 in Canada, 7 in Eastern Europe, and 8 in Australia/South Africa) enrolled 11484 patients between April 1999 and July 2000, with the last patient visit on April 18, 2001. The groups were well matched and consistent with the expected moderate risk of restenosis based on the proportion of patients with factors known to be associated with restenosis (Table 1). The mean number of target vessels was 1.2, and the mean number of target lesions was 1.4 .

The angiographic subset $(n=2018)$ was not clinically different from the population as a whole or from a random sample of patients not in the angiographic subset: $77 \%$ were male, $40 \%$ had a previous MI, $24 \%$ were diabetic, and $13 \%$ underwent PCI after an MI. The mean numbers of target vessels and lesions were identical to those of the general population: $15 \%$ had restenotic lesions, $12 \%$ had in-stent restenosis, and $83 \%$ received a stent. The IVUS population $(n=1107)$ was similar to the PRESTO population and similar to a random sample of patients not in the angiography subset (data not shown). However, there was some evidence that the patients in the IVUS subset had larger vessel diameters (mean stent diameter of 3.4 versus $3.2 \mathrm{~mm}$ for the angiographic subset). A total of 1180 lesions were evaluated by IVUS; only $73(6 \%)$ were in nonstented vessels.

\section{MACE During 9 Months}

The frequency of the first occurrence of MACE in the placebo group was slightly lower than predicted (15.7\%). The MACE rate was virtually identical among all 4 tranilast groups, and there was no decrease from placebo (Table 2). MACE rates were driven by ischemia-induced target vessel revascularization; the frequency of death and MIs were low, occurring in only $1 \%$ to $1.8 \%$ of the population (Figure 1). Extensive subgroup analyses were performed. The relative risk of MACE by subgroups (Figures 2 and 3) revealed no differences between tranilast and placebo in any subgroup. As expected, mortality was low in this study population. No

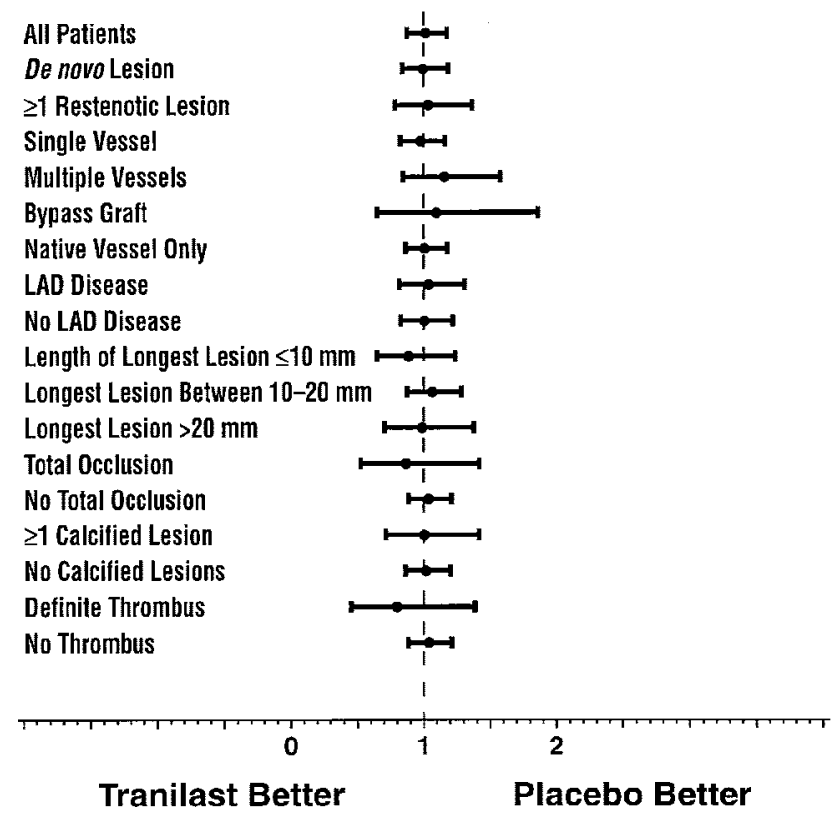

Figure 2. Subgroup analyses of MACE outcome differences between placebo and tranilast.

trends in favor of any dose of tranilast were observed for death or ischemia-driven target vessel revascularization. To test whether early withdrawals were responsible for the lack of effect, an analysis was performed in patients who completed treatment with no treatment effect observed.

A possible trend in favor of tranilast (450 mg BID) compared with placebo was observed in the frequency of follow-up MIs (hazard ratio $0.62,95 \%$ CI 0.38 to 1.03; $P=0.061$ ). To ascertain the strength of this trend, an analysis of patients who completed at least 84 days of treatment was undertaken; the hazard (tranilast/placebo) ratio for follow-up

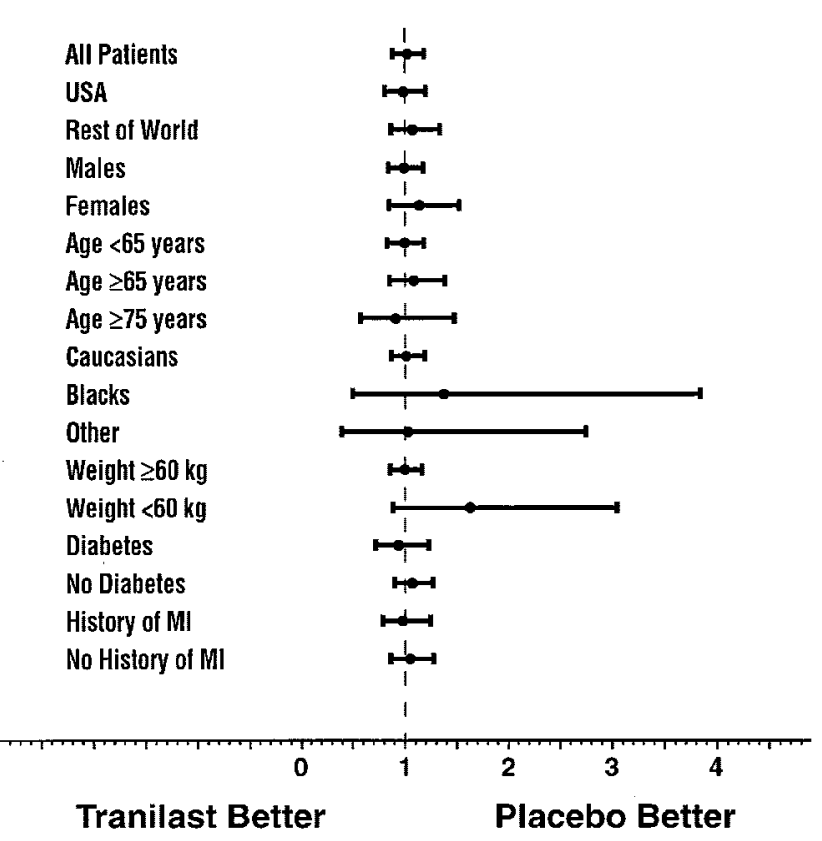

Figure 3. Subgroup analyses of MACE outcome differences between placebo and tranilast. 
TABLE 3. Quantitative Angiographic Analysis

\begin{tabular}{|c|c|c|c|c|c|}
\hline \multirow[b]{2}{*}{ Angiographic End Points by Patient } & \multirow[b]{2}{*}{$\begin{array}{l}\text { Placebo } \\
(\mathrm{n}=420)\end{array}$} & \multicolumn{2}{|c|}{ Tranilast BID for $1 \mathrm{mo}$} & \multicolumn{2}{|c|}{ Tranilast BID for $3 \mathrm{mo}$} \\
\hline & & $\begin{array}{l}300 \mathrm{mg} \\
(\mathrm{n}=407)\end{array}$ & $\begin{array}{l}450 \mathrm{mg} \\
(\mathrm{n}=389)\end{array}$ & $\begin{array}{l}300 \mathrm{mg} \\
(\mathrm{n}=415)\end{array}$ & $\begin{array}{l}450 \mathrm{mg} \\
(\mathrm{n}=387)\end{array}$ \\
\hline \multicolumn{6}{|l|}{ Baseline } \\
\hline Reference diameter, mm & $2.90 \pm 0.51$ & $2.92 \pm 0.54$ & $2.94 \pm 0.52$ & $2.93 \pm 0.51$ & $2.92 \pm 0.57$ \\
\hline MLD, mm & $0.81 \pm 0.43$ & $0.86 \pm 0.48$ & $0.79 \pm 0.47$ & $0.85 \pm 0.45$ & $0.83 \pm 0.42$ \\
\hline Stenosis, \% & $72.1 \pm 14.2$ & $71.1 \pm 14.6$ & $73.0 \pm 14.9$ & $70.8 \pm 14.9$ & $71.6 \pm 13.2$ \\
\hline MLD immediately after $\mathrm{PCl}, \mathrm{mm}$ & $2.70 \pm 0.56$ & $2.69 \pm 0.60$ & $2.72 \pm 0.58$ & $2.74 \pm 0.56$ & $2.74 \pm 0.62$ \\
\hline Acute gain in MLD, mm & $1.89 \pm 0.64$ & $1.83 \pm 0.63$ & $1.94 \pm 0.67$ & $1.89 \pm 0.65$ & $1.91 \pm 0.64$ \\
\hline Residual stenosis, \% & $10.0 \pm 11.9$ & $10.5 \pm 13.1$ & $9.5 \pm 12.4$ & $9.3 \pm 12.4$ & $9.7 \pm 11.6$ \\
\hline MLD at follow-up, ${ }^{\star} \mathrm{mm}$ & $1.76 \pm 0.77$ & $1.72 \pm 0.80$ & $1.77 \pm 0.76$ & $1.75 \pm 0.79$ & $1.78 \pm 0.77$ \\
\hline $\begin{array}{l}\text { Change in MLD from immediately after } \\
\mathrm{PCl} \text { (late loss), mm }\end{array}$ & $0.96 \pm 0.76$ & $0.972 \pm 0.75$ & $0.972 \pm 0.79$ & $1.00 \pm 0.79$ & $0.97 \pm 0.76$ \\
\hline$\%$ Stenosis at follow-up & $39.5 \pm 23.8$ & $40.5 \pm 24.0$ & $38.8 \pm 23.1$ & $39.7 \pm 23.4$ & $38.7 \pm 22.9$ \\
\hline Ratio of late loss/acute gain & $0.52 \pm 0.45$ & $0.57 \pm 0.50$ & $0.49 \pm 0.48$ & $0.54 \pm 0.44$ & $0.52 \pm 0.41$ \\
\hline \multicolumn{6}{|l|}{ Restenosis rate: $\geq 50 \%$ stenosis } \\
\hline Lesions, \% & 30.1 & 29.8 & 28.5 & 29.8 & 29.0 \\
\hline Patients, $† \%$ & 33.3 & 35.1 & 33.4 & 35.2 & 32.3 \\
\hline
\end{tabular}

MI decreased to 0.44 (95\% CI 0.23 to 0.85$)$, and the significance was $P=0.012$.

\section{Angiographic and IVUS Results}

Informed consent was given by 2682 patients for the angiographic substudy, and follow-up was terminated when 2018 patient follow-up films had been submitted to the core laboratories $(75 \%)$. At the time of the index procedure, the mean target vessel reference diameters and MLD as well as the percent stenosis and residual stenosis were similar across treatment groups. There were no statistically or clinically significant differences in the angiographic variables immediately after the index PCI or at follow-up (Table 3). These data are represented in Figure 4 by the cumulative curves of MLD in the placebo group and the highest dose/duration of the tranilast group.

Angiographic restenosis by patient and lesion (Table 3) showed no significant differences between tranilast and

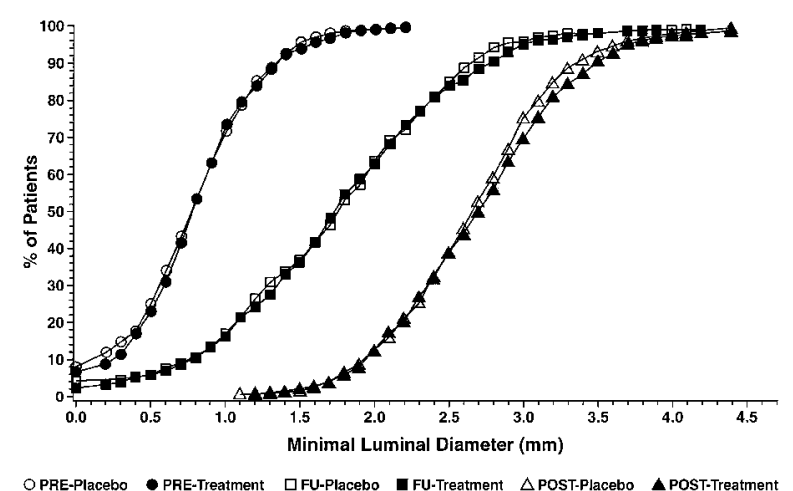

Figure 4. Cumulative distribution curves of MLD for highest dose/duration of tranilast (450 mg BID for 3-month group) compared with placebo. placebo ( $P=0.46$ to 1.00 ). However, there was a significant $(P<0.001)$ correlation between the frequency of restenosis across treatment groups and the occurrence of MACE (Table 4). This was again related to target vessel revascularization. Patients who had no evidence of restenosis with $\geq 50 \%$ stenoses by angiography were significantly less likely to have a MACE.

There were no clinically or statistically significant differences among the treatment groups in any of the intracoronary ultrasound measurements (Table 5).

\section{Adverse Events}

The most frequently reported adverse experiences were laboratory test abnormalities consisting of hyperbilirubinemia, elevations in hepatic (transaminase) enzymes, and hepatic function abnormal (Table 6). In addition, there were increases in serum creatinine and decreases in hemoglobin reported as anemia. The majority of the increases in serum creatinine

TABLE 4. Correction Between Angiographic Restenosis and MACE

\begin{tabular}{llcc}
\hline & \multicolumn{3}{c}{ Angiographic Restenosis } \\
\cline { 2 - 3 } Association With & \multicolumn{2}{c}{$\geq 50 \%$ Stenosis } & \\
\cline { 2 - 3 } Restenosis & Yes, $\mathrm{n}(\%)$ & No, $\mathrm{n}(\%)$ & Total, n (\%) \\
\hline MACE & $313(46)^{*}$ & $73(5)$ & $386(19)$ \\
Yes & $371(54)$ & $1261(95)^{\star}$ & $1632(81)$ \\
No & $684(100)$ & $1334(100)$ & $2018(100)$ \\
\hline
\end{tabular}

*Positive predictive value $=313 / 684=0.458( \pm 0.019)$; negative predictive value $=1261 / 1334=0.945( \pm 0.006) ; P$ value from $\chi^{2}$ test for association $(P<0.001)$. 
TABLE 5. IVUS Analysis at Follow-Up of Patients Who Had at Least 1 Stented Vessel

\begin{tabular}{|c|c|c|c|c|c|}
\hline \multirow[b]{2}{*}{ IVUS End Points at Follow-Up } & \multirow[b]{2}{*}{$\begin{array}{l}\text { Placebo } \\
(n=224)\end{array}$} & \multicolumn{2}{|c|}{ Tranilast BID for 1 mo } & \multicolumn{2}{|c|}{ Tranilast BID for 3 mo } \\
\hline & & $\begin{array}{l}300 \mathrm{mg} \\
(\mathrm{n}=211)\end{array}$ & $\begin{array}{l}450 \mathrm{mg} \\
(\mathrm{n}=222)\end{array}$ & $\begin{array}{l}300 \mathrm{mg} \\
(\mathrm{n}=230)\end{array}$ & $\begin{array}{l}450 \mathrm{mg} \\
(\mathrm{n}=220)\end{array}$ \\
\hline \multicolumn{6}{|l|}{ Plaque volume, $\mathrm{mm}^{3}$} \\
\hline Mean \pm SD & $39.3 \pm 26.2$ & $37.5 \pm 26.9$ & $45.3 \pm 32.3$ & $45.5 \pm 47.1$ & $46.1 \pm 36.7$ \\
\hline$P$ vs placebo & $\cdots$ & 0.72 & 0.22 & 0.20 & 0.16 \\
\hline \multicolumn{6}{|l|}{ Mean luminal area, $\mathrm{mm}^{2}$} \\
\hline Mean $\pm S D$ & $5.5 \pm 1.94$ & $5.9 \pm 2.27$ & $5.2 \pm 2.19$ & $5.7 \pm 2.45$ & $5.5 \pm 2.63$ \\
\hline$P$ vs placebo & $\ldots$ & 0.19 & 0.42 & 0.42 & 0.93 \\
\hline \multicolumn{6}{|l|}{ Plaque area, $\mathrm{mm}^{2}$} \\
\hline Mean $\pm S D$ & $2.7 \pm 2.61$ & $2.4 \pm 2.45$ & $2.7 \pm 2.13$ & $2.3 \pm 1.56$ & $2.7 \pm 2.23$ \\
\hline$P$ vs placebo & $\ldots$ & 0.32 & 0.93 & 0.16 & 0.97 \\
\hline \multicolumn{6}{|l|}{ Mean total vessel area, $\mathrm{mm}^{2}$} \\
\hline Mean $\pm S D$ & $5.7 \pm 3.0$ & $6.9 \pm 3.0$ & $7.4 \pm 3.2$ & $6.2 \pm 3.5$ & $4.8 \pm 2.8$ \\
\hline$P$ vs placebo & $\ldots$ & 0.33 & 0.17 & 0.71 & 0.50 \\
\hline
\end{tabular}

were $50 \%$ increases to values $>1.2 \mathrm{mg} / \mathrm{dL}$. Less than $1 \%$ of the patients in all treatment groups had a serum creatinine $\geq 2$ $\mathrm{mg} / \mathrm{dL}$ at the termination of double-blind treatment. The hepatic and renal laboratory abnormalities as well as anemia were related to both the dose of tranilast and the duration of tranilast treatment (ie, the higher the dose and the longer the duration of treatment, the higher was the frequency). These laboratory abnormalities, when followed, were all reversible with discontinuation of the study medication.

\section{Discussion}

Tranilast was not significantly more effective than placebo at total daily doses of 600 and $900 \mathrm{mg}$ a day administered for 1 or 3 months in reducing the frequency of MACE or angiographic restenosis in a broad group of patients undergoing PCI. In addition, it did not decrease neointimal hyperplasia as measured by IVUS. The incidence of MACE in the placebo group was $15.7 \%$, and the incidence of MACE in the tranilast groups ranged from $15.5 \%$ to $15.0 \%$. In the angiographic

TABLE 6. Most Frequently ( $\geq 2 \%$ ) Reported Adverse Experiences Considered at Least Possibly Related to Tranilast

\begin{tabular}{|c|c|c|c|c|c|}
\hline \multirow{2}{*}{$\begin{array}{l}\text { WHO Body System and Preferred } \\
\text { Term }\end{array}$} & \multirow[b]{2}{*}{ Placebo } & \multicolumn{2}{|c|}{$\begin{array}{l}\text { Tranilast BID for } 1 \\
\text { mo }\end{array}$} & \multicolumn{2}{|c|}{$\begin{array}{l}\text { Tranilast BID for } 3 \\
\text { mo }\end{array}$} \\
\hline & & $300 \mathrm{mg}$ & $450 \mathrm{mg}$ & $300 \mathrm{mg}$ & $450 \mathrm{mg}$ \\
\hline \multicolumn{6}{|l|}{ Gastrointestinal } \\
\hline Abdominal pain, \% & $<1$ & $<1$ & 1 & 2 & 2 \\
\hline Nausea, \% & 1 & 1 & 2 & 1 & 2 \\
\hline \multicolumn{6}{|l|}{ Liver/biliary system } \\
\hline Hyperbilirubinemia, \% & $<1$ & 2 & 8 & 4 & 12 \\
\hline Hepatic function abnormal, \% & $<1$ & 5 & 7 & 7 & 9 \\
\hline Hepatic enzymes increased, \% & $<1$ & 3 & 4 & 5 & 6 \\
\hline SGPT increased, \% & 1 & 2 & 3 & 3 & 3 \\
\hline \multicolumn{6}{|l|}{ Metabolic } \\
\hline Creatinine increased, \% & 1 & 2 & 3 & 3 & 5 \\
\hline \multicolumn{6}{|l|}{ Red blood cells } \\
\hline Anemia, \% & $<1$ & $<1$ & 2 & 1 & 4 \\
\hline \multicolumn{6}{|l|}{ Skin and appendages } \\
\hline Rash, \% & 1 & $<1$ & $<1$ & 1 & 2 \\
\hline \multicolumn{6}{|l|}{ Urinary system } \\
\hline Dysuria, \% & $<1$ & 2 & 2 & 2 & 3 \\
\hline
\end{tabular}

WHO indicates World Health Organization; SGPT, serum glutamic pyruvic transaminase. Events within body system are not additive because some patients are counted in multiple preferred terms listed under body system.

*Procedural injury includes hematoma, pain, oozing, pseudoaneurysm, and bruising at catheter insertion sight. 


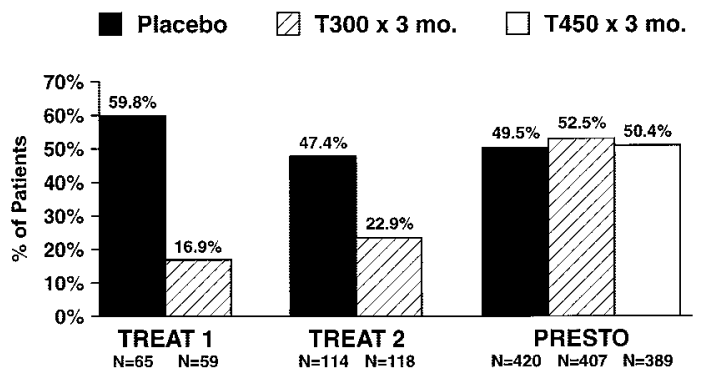

KEY: $\mathrm{T} 300 \times 3 \mathrm{mo}=$ tranilast, $300 \mathrm{mg}$ bid for three months and $\mathrm{T} 450 \times 3 \mathrm{mo}$. = tranilast, $\mathbf{4 5 0} \mathrm{mg}$ bid for three months.

Figure 5. Restenosis defined as $\geq 50 \%$ loss of acute gain in PRESTO vs TREAT 1 and TREAT 2 trials.

substudy, a $\geq 50 \%$ loss of acute gain was found in $50 \%$ of the patients treated with placebo and in $49 \%$ to $52 \%$ of the patients treated with tranilast. These findings are in contrast to the statistically significant and clinically relevant restenosis rates associated with tranilast treatment observed previously in the Tranilast Restenosis Following Angioplasty Trial (TREAT trial) (Figure 5). ${ }^{5,6}$ In the TREAT 1 trial, ${ }^{5}$ MLD at follow-up was $1.54 \mathrm{~mm}$ in the placebo group and $1.82 \mathrm{~mm}$ in the tranilast $(600 \mathrm{mg})$ group $(P=0.001)$. The MLD in the PRESTO trial at follow-up in the tranilast group was $1.76 \mathrm{~mm}$, which was not different from that observed with tranilast (600 mg for 3 months) in the TREAT trial. What is different is that the MLD in the placebo group in the PRESTO trial was larger (at $1.75 \mathrm{~mm}$ ). Immediately after PCI, the MLD in the TREAT 1 trial was significantly larger in the tranilast group than in the placebo group (2.27 versus $1.54 \mathrm{~mm}$, respectively; $P=0.029)$. MLD was not reported for the TREAT 2 trial. $^{6}$

In the TREAT trials, restenosis defined as a $\geq 50 \%$ loss of acute gain was reported for $17 \%$ and $23 \%$ (Figure 5) of the patients. TREAT 1 reported that $43.1 \%$ of the placebo-treated patients had $\mathrm{a} \geq 50 \%$ stenosis compared with $20.3 \%$ of the patients treated with tranilast (600 mg a day). Compared with the PRESTO trial, these trials were small and generally included patients at lower risk of restenosis. In the TREAT 1 trial, 85 or 86 patients per treatment group were randomized, and in the second TREAT trial, 114 to 118 were randomized. These trials excluded lesions in the side branches, left main disease, grafts, lesions $>20 \mathrm{~mm}$, lesions responsible for MIs within 2 weeks of study entry, patients with no thrombus or dissection, and Thrombolysis in Myocardial Infarction (TIMI) grades $>1$. All of these exclusion criteria were allowed in the PRESTO trial. In the TREAT trials, patients who did not complete treatment were eliminated from analysis; $\approx 28 \%$ of the patients were excluded. The PRESTO analysis was an intent-to-treat whereby all patients who received at least 1 dose of medication were included.

Two trials reported the frequency of MACE during a 1-year follow-up. In the TREAT 1 study, ${ }^{5}$ there were no MIs or deaths. In the second, a concurrent control study in patients who underwent directional coronary atherectomy (DCA), ${ }^{16}$ the frequency of MI was $0.7 \%$ in the DCA-only group compared with $0 \%$ in the DCA plus tranilast $(600 \mathrm{mg}$ a day for 3 months) group. These frequencies are based on a denominator of patients who completed the 3 months of treatment and were valid for efficacy analyses. To make like comparisons, the frequency of $\mathrm{MI}$ in the placebo group for those patients who completed 84 days in the PRESTO trial was calculated, and among those patients, a significant reduction in the frequency of $\mathrm{MI}$ was seen in the 3-month tranilast (450 mg BID) group compared with the placebo group $(0.4 \%$ versus $1.6 \%$, respectively; $P=0.002)$. The beneficial effect of tranilast on the frequency of MIs may, in part, be due to its attenuation of the proinflammatory activity of human monocytes/macrophages. ${ }^{7}$ Alternately, the reduction in the frequency of MIs may be the result of multiple analyses on multiple end points and, therefore, may be spurious.

Although there were no differences between the tranilast and placebo groups in the primary efficacy end point of MACE and in the secondary efficacy end point of angiographic restenosis, there were both dose-related and durationrelated laboratory test abnormalities reported as adverse experiences. These abnormalities were reversible on the cessation of tranilast treatment. The adverse experience profile in the present study was similar to that reported by Tamai and colleagues. ${ }^{5,6} \mathrm{Had}$ the study met the primary efficacy criteria, it was believed that the benefit of reducing the incidence of MACE would outweigh the risk. However, even if the benefit observed in the reducing subsequent MIs proved to be reproducible, this advantage would probably still not outweigh the risk of developing liver laboratory test abnormalities.

The lack of efficacy demonstrated by tranilast in the PRESTO study was unexpected and clearly failed to confirm earlier reports. ${ }^{5,6,10,16}$ This underscores and emphasizes the critical importance of subjecting the findings of studies limited in scope and sample size (even when "statistically significant") to robust, large-scale, definitive trials adequately powered to avoid type I errors.

Prevention of restenosis has been very difficult but remains very important because of recurrent symptoms and the need for subsequent procedures when restenosis occurs. Multiple device and medication strategies have been tested; typically, small experimental or pilot human studies form the rationale for larger more definitive studies. These larger definitive studies are aimed at overcoming the limitations of small studies. The PRESTO trial followed the same time course of other investigations, from small pilot studies to a definitive large study, which in this case was negative. Ever since the design and performance of the PRESTO trial, new data have accumulated that appear encouraging. Information continues to accumulate on the efficacy of vascular brachytherapy for treatment of in-stent restenosis (although not for prevention of initial restenosis). Even more exciting are the initial data on drug-coated stents, which dramatically prevent restenosis.

In conclusion, in this multicenter, large, randomized clinical trial, administration of tranilast in 2 different doses for 2 different durations was associated with no improvement in either angiographic or clinical restenosis compared with administration of placebo alone. 


\section{Appendix}

\section{Institutions and Investigators}

Institutions and investigators who enrolled at least 45 patients in the PRESTO trial can be found in the online version of the present study, available at http://circ.ahajournals.org.

\section{Core Laboratories}

The authors wish to acknowledge the assistance in reading angiograms and IVUS films, which is contained in the online version of the present study.

\section{Acknowledgments}

This study was supported by grants from GlaxoSmithKline Pharmaceuticals. The authors wish to acknowledge Trish A. McBride, BSN, Patricia Adams, MS, Barbara D, Fisher, BS, and Caroline Aitken, BSc, for the in-life study supervision. In addition, statistical analyses were performed by Nicole Blackman, MS.

\section{References}

1. Fischman DL, Leon MB, Baim DS, et al, for STRESS (Stent Restenosis Study Investigators). A randomized comparison of coronary-stent placement and balloon angioplasty in the treatment of coronary artery disease. N Engl J Med. 1994;331:496-501.

2. Savage MP, Fischman DL, Rake R, et al. Efficacy of coronary stenting vs balloon angioplasty in small coronary arteries. J Am Coll Cardiol. 1998; 31:307-311.

3. Serruys PW, deJaegere M, Kiemaeneig F, et al, for the Benestent Study Group. A comparison of balloon-expandable-stent implantation with balloon angioplasty in patients with coronary artery disease. $N$ Engl J Med. 1994;331:489-495.

4. Nobuyoshi M, Kimura T, Nosaka H, et al. Restenosis after successful coronary angioplasty: serial angiographic follow-up of 229 patients. $J \mathrm{Am}$ Coll Cardiol. 1988;12:616-623.
5. Tamai H, Katoh O, Suzuki S. Impact of tranilast on restenosis after coronary angioplasty: Tranilast Restenosis Following Angioplasty Trial (TREAT). Am Heart J. 1999;138:968-975.

6. Tamai H, for the Treat Group. Inhibitory effect of tranilast on restenosis after percutaneous transluminal coronary angioplasty (PTCA): a phase III multicenter randomized double blind placebo-controlled trial. J Clin Ther Med. 1996;12:65-85.

7. Capper EA, Roshak AK, Bolognese BJ, et al. Modulation of human monocyte activities by Tranilast, SB 252218, a compound demonstrating efficacy in restenosis. J Pharmacol Exp Ther. 2000;295:1061-1069.

8. Fukuyama J, Ichikawa K, Hamano S, et al. Tranilast suppresses the vascular intimal hyperplasia after balloon injury in rabbits fed a high cholesterol diet. Eur J Pharmacol. 1996;318:327-332.

9. Ishikwata S, Verheye S, Robinston KA, et al. Inhibition of neointima formation by tranilast in pig coronary arteries after balloon angioplasty and stent implantation. J Am Coll Cardiol. 2000;35:1331-1337.

10. Hsu YS, Tamai H, Lleda K, et al. Efficacy of tranilast on restenosis after coronary stenting. Circulation. 1996;94(suppl I):I-620. Abstract.

11. Holmes D, Fitzgerald P, Goldberg S. The PRESTO (Prevention of Restenosis With Tranilast and Its Outcomes) protocol: a double-blind, placebocontrolled trial. Am Heart J. 2000;139:23-31.

12. The EPISTENT Investigators. Randomized placebo-controlled and balloon-angioplasty-controlled - controlled trial to assess safety and coronary stenting with use of platelet glycoprotein IIb/IIIa blockade. Lancet. 1998;352:87-92.

13. Schoenfeld DA, Richter JG. Nomograms for calculating the number of patients needed for a clinical trial with survival as an endpoint. Biometrics. 1982;38:163-170.

14. Haybittle JL. Repeated assessment of results in clinical trials of cancer treatment. Br J Radiol. 1971;44:793-797.

15. Hochberg Y. A sharper Bonferroni procedure for multiple tests and significance. Biometrika. 1988;75:800-802.

16. Kosuga K, Tamai H, Uedo K, et al. Effectiveness of tranilast on restenosis after directional coronary atherectomy. Am Heart J. 1997; 134:712-718. 